\title{
A FRAMEWORK FOR AN OPEN SOURCE GEOSPATIAL CERTIFICATION MODEL
}

\author{
T. U. R. Khan ${ }^{\text {a }}$, P. Davis ${ }^{\text {b }}$, F.-J. Behr ${ }^{\text {a* }}$ \\ ${ }^{\text {a }}$ Department of Geomatics, Computer Science and Mathematics, Stuttgart University of Applied Sciences, Stuttgart, Germany - \\ franz-josef.behr@hft-stuttgart.de, tanzeelrehman130@hotmail.com \\ b Del Mar College, Director GeoAcademy, Del Mar College, Corpus Christi, Texas, USA - pdavis@ delmar.edu
}

Commission VI, WG VI/3

KEY WORDS: Geospatial certification, Open Source, Geospatial Technology Competency Model, OSGeo

\begin{abstract}
:
The geospatial industry is forecasted to have an enormous growth in the forthcoming years and an extended need for well-educated workforce. Hence ongoing education and training play an important role in the professional life. Parallel, in the geospatial and IT arena as well in the political discussion and legislation Open Source solutions, open data proliferation, and the use of open standards have an increasing significance. Based on the Memorandum of Understanding between International Cartographic Association, OSGeo Foundation, and ISPRS this development led to the implementation of the ICA-OSGeo-Lab imitative with its mission "Making geospatial education and opportunities accessible to all". Discussions in this initiative and the growth and maturity of geospatial Open Source software initiated the idea to develop a framework for a worldwide applicable Open Source certification approach.
\end{abstract}

Generic and geospatial certification approaches are already offered by numerous organisations, i.e., GIS Certification Institute, GeoAcademy, ASPRS, and software vendors, i. e., Esri, Oracle, and RedHat. They focus different fields of expertise and have different levels and ways of examination which are offered for a wide range of fees.

The development of the certification framework presented here is based on the analysis of diverse bodies of knowledge concepts, i.e., NCGIA Core Curriculum, URISA Body Of Knowledge, USGIF Essential Body Of Knowledge, the "Geographic Information: Need to Know", currently under development, and the Geospatial Technology Competency Model (GTCM). The latter provides a US American oriented list of the knowledge, skills, and abilities required of workers in the geospatial technology industry and influenced essentially the framework of certification.

In addition to the theoretical analysis of existing resources the geospatial community was integrated twofold. An online survey about the relevance of Open Source was performed and evaluated with 105 respondents worldwide. 15 interviews (face-to-face or by telephone) with experts in different countries provided additional insights into Open Source usage and certification.

The findings led to the development of a certification framework of three main categories with in total eleven sub-categories, i.e., "Certified Open Source Geospatial Data Associate / Professional", "Certified Open Source Geospatial Analyst Remote Sensing \& GIS", "Certified Open Source Geospatial Cartographer", "Certified Open Source Geospatial Expert", "Certified Open Source Geospatial Associate Developer / Professional Developer", "Certified Open Source Geospatial Architect". Each certification is described by pre-conditions, scope and objectives, course content, recommended software packages, target group, expected benefits, and the methods of examination. Examinations can be flanked by proofs of professional career paths and achievements which need a peer qualification evaluation. After a couple of years a recertification is required.

The concept seeks the accreditation by the OSGeo Foundation (and other bodies) and international support by a group of geospatial scientific institutions to achieve wide and international acceptance for this Open Source geospatial certification model.

A business case for Open Source certification and a corresponding SWOT model is examined to support the goals of the Geo-ForAll initiative of the ICA-OSGeo pact.

\section{INTRODUCTION}

In the growing industry of geospatial technology, skilled and certified professionals are needed (DiBiase et al. 2006, Steudler et al. 2010, AAG 2012, Richardson 2013, Davis 2015). Geospatial workforce needs are identified based on different competencies and skills. With the increasing importance of
Open Source the related certification can be a significant boost for the geospatial industry and particular for the branches of the industry dealing with Open Source, Open Data, Open Standards, and Open Education.

\footnotetext{
* Corresponding author
} 
As an indicator of someone's competencies some sort of demonstrated qualifications and certifications are important. Certification refers here to the process of assuring that individuals' possess adequate knowledge, skills, and defined competences in a profession. According to Careeronestop (2015a) a competency "is the capability to apply or use a set of related knowledge, skills, and abilities required to successfully perform 'critical work functions' or tasks in a defined work setting”.

In the Geographical Information System (GIS) profession, academia and industry certifications are most common (DiBiase, 2003). In the general IT however current certifications are mostly offered for proprietary software, whereas Open Source software, especially in the geospatial field, has opened new horizons for educators and researchers because of its flexibility and security (Petras et al. 2015). Currently there is a need of certification for Open Source which enables user to unfold many new tools within Open Source, open standards, and open data (Christl 2014). This certification uses competencies which are depicted by the "Geospatial Technology Competency Model" (GTCM) that was developed by the US Department of Labour under supervision of experts and educators since 2010. This certification is expected to support the provision of great technical workforce in geospatial industry.

The basis for the creation of the proposed Open Source geospatial certification program lies in the analysis of existing certifications, in personal interviews as well in a worldwide online survey of academic and professional for its market demand. Participants from different parts of the world supported and reinforced the idea of an Open Source certification model. The survey helped improving the quality of certification for different competencies focusing different target groups.

Certification needs a thorough and professional handling and organisation. Hence a business model and a SWOT analysis were conducted to conceptualize a business for open solutions.

\section{LITERATURE REVIEW AND ANALYSIS OF EXISTING CERTIFICATIONS}

Generic and geospatial certification approaches are already offered by numerous geo-oriented organisations, i.e., GIS Certification Institute, GeoAcademy, ASPRS, and software vendors, i. e., Esri, Oracle, and RedHat. They focus different fields of expertise and have different levels and ways of examination which are offered for a wide range of fees. The following sections summarize some existing certifications. For further examples see Horak (2015).

\subsection{American Society of Photogrammetry and Remote Sensing (ASPRS)}

For the American Society of Photogrammetry and Remote Sensing (ASPRS) certification is "official recognition by one's colleagues and peers that an individual has demonstrated professional integrity and competence in their field" (APSRS 2016c). ASPRS offers different types of technological and professional certifications including (ASPRS 2016a):

1. Certified Photogrammetrist

2. Certified Mapping Scientist - Remote Sensing

3. Certified Mapping Scientist - GIS/LIS
4. Certified Mapping Scientist - Lidar

5. Certified Photogrammetric Technologist

6. Certified Remote Sensing Technologist

7. Certified GIS/LIS Technologist

8. Certified Lidar Technologist

The applicant has to prove knowledge and a wide range of professional fields, i.e. Math/Science, Engineering/Surveying, Physics, Imaging, Photogrammetry, GIS, LiDAR, Ethics/General.

For active students APSRS offers the "Geospatial Intern status". In this case no on-job experience is required.

To get a professional certification applicants have to proof demonstrated professional capabilities and professional references and have to go through a peer-review of experience and training, and pass the written examination for the specialty area. This approach exemplifies competence-based certification, in which candidates must demonstrate their mastery of a common body of knowledge within their profession by examination (DiBiase et al., 2006).

Basically certification is granted for life. However ASPRS offers the option of recertification to certified professionals after five years of previous certification. In addition to references a certain amount of credits according to a list of criteria that will be reviewed by the evaluation for Certification Committee. After this demonstration of maintenance or improvement on skills and knowledge the applicant can be part of the Active Certified List..

Compliance with the ASPRS Code of Ethics plays an additional significant role in the examination process.

\subsection{GIS Certification Institute}

The GIS Certification Institute (GISCI, https://www.gisci.org/) was implemented in 2003 with representatives from Urban and Regional Systems Association (URISA), Association of American Geographers (AAG), University Consortium for Geographic Information Science (UCGIS), and National States Geographic Information Council (NSGIC) (Wikle, 2014). This non-profit organization offers an opportunity to candidates for international recognition by certifications from early job years to retirement. The following table summarizes the technical areas focused in GISCI certification examination.

\begin{tabular}{|c|c|}
\hline Focus Area & Weightage \\
\hline Conceptual Foundations & $12 \%$ \\
\hline Cartography and Visualizations & $14 \%$ \\
\hline GIS Design Aspects and Data Modelling & $29 \%$ \\
\hline GIS analytical Methods & $17 \%$ \\
\hline Data Manipulation & $15 \%$ \\
\hline Geospatial Data & $13 \%$ \\
\hline
\end{tabular}

Table 1: List of examination areas (source: Somers 2015)

GISCI's Geographic Information Systems Professional (GISP) certification program requires individuals only to document relevant qualifications regarding educational achievements, professional experience, and contributions to the profession. Similar to ASPRS's approach the applicants have to affirm their commitment to ethical practices. 
Their body of knowledge (BOK) provides a basis for the assessment of the applicants' competencies to the GISCI program (DiBiase et al., 2006, Horak 2015). One individual can achieve the certification if she/he has met all required standards in terms of experience, education, and contribution (Somers, 2004). Based on BOK, GISCI certification program certifies individuals in the single category of GIS professional.

\subsection{Esri Technical Certifications}

Esri provides three levels of certifications: desktop, developer and enterprise related to technical expertise with Esri tools and technology. The certification packages need familiarity and advanced knowledge and working experience with the ArcGIS family software (Esri 2015).

Esri technical certification is computer based exam of two hours duration, containing 90-95 multiple choice questions. They issue result after five days via email to individual candidates. A retake is also possible within 14 days if failed in first attempt but second retake is only possible after 90 days (Esri 2015).

\subsection{Oracle Certifications}

Oracle University offers many application packages including associate, professional, master, specialist and expert certifications. After becoming an Oracle Certified, the candidate get better standing in competitive job market as certifications add value to his/her current technical job experience(Oracle 2015). In all packages of Oracle certifications, multiple choice questions are given with varying durations which have different passing percentages to obtain the certification. There are also certain exam topics which are necessary to pass the exam (Oracle 2015).

\subsection{The Meta Spatial Institute}

Metaspatial Institute (http://www.metaspatial.net/en/institute) tries to open a new horizon of certifications for geospatial professionals in Open Source technology by offering an independent third party certification for companies and their professional staff to enhance the expertise in Open Source software (Metaspatial Institute 2015). Focusing three geospatial domains, i.e., Open Source, open standards and open data, they seek to offer five types of professional certification:

$\begin{array}{ll}\text { 1. } & \text { Open Source Geospatial Software Developer } \\ \text { 2. } & \text { Open Source Geospatial Software Professional } \\ \text { 3. } & \text { Open Geospatial Data Professional } \\ \text { 4. } & \text { Open Geospatial Standards Expert } \\ \text { 5. } & \text { Open Geospatial Consultant }\end{array}$

In the first stage the candidate has to pass an online test. After successful completion the candidate has to send his/her curriculum vitae with previous work experience and referrals. The Metaspatial Institute evaluates the documents and, if the candidate is successful, they invite the candidate for a technical interview. This is the most challenging phase of the process as the interview focuses more on technical aspects and on interviewer personality. One can attend conferences, congresses, and workshops or trainings at his/her own for the preparation of the examination, for example through a partner network of training provides. Also this approach is an example of competence-based certification with its characteristic to focus Open Source.

\section{6 gvSIG Certification}

Another Open Source certification is recently offered by the gvSIG association (gvSIG Association 2015). It comprises two types of certification:

1. gvSIG Desktop Expert Certification

2. gvSIG Desktop Users Certification

The certification is based on credits which must be achieved in different modules from gvSIG introduction to scripting and processing of vector data. The candidate has to learn basic functionalities of gvSIG, basic working with projection and reprojection tools, image georeferencing and provides basics about gvSIG mobile application.

After user certification on expert level gvSIG Expert Certification encompasses advanced functions and advanced analysis.

\subsection{Further national certification approaches}

In Pakistan particularly PIMS (2015) offers distance learning education program in which different professional certifications, diploma, and post graduate diplomas are included. They offer one of the top level certification in Pakistan called Certified Professional Manager in GIS (PIMS 2015). In this case certification requires at least 12 years of education, industry related experience in GIS, and participation in some educational modules.

Horak (2015) provides further examples for European countries.

\section{INVESTIGATION OF GEOSPATIAL TECHNOLOGY COMPETENCY MODEL (GTCM)}

Since decades, business and education has utilized competency models to educate and to select employees (Ennis 2008). According to Careeronestop (2015a) such a competency model is a "collection of multiple competencies that together define successful performance in a defined work setting. A model provides a clear description of what a person needs to know and be able to do - the knowledge, skills, and abilities - to perform well in a specific job, occupation, or industry".

The Geospatial Technology Competency Model is an implementation of the building blocks approach (CarreerOneStop 2015b). It was developed by Employment and Training Administration (ETA), Geotech centre and industry experts in 2010 and revised in 2014.

As depicted in Fig. 1 the first three tiers comprise foundational competencies, i.e., user's personal effectiveness, academic and workplace competencies. Tier 4 and 5 contain industry wide and industry specific technical competencies, and tier 6 to 9 occupation related competencies (Tier 6: Occupation-Specific Knowledge Competencies, Tier 7: Occupation-Specific Technical Competencies, Tier 8:Occupation-Specific Requirements, Tier 9: Management Competencies).

Based on this structure GTCM defines different core geospatial abilities and knowledge, i.e. 43 core geospatial competencies regarding geospatial occupation, and additional 19-24 essential competencies for each of three industry sectors like positioning and data acquisitioning, data analysis and modelling, and software programming and application development. Tier 6 
defines occupation specific field competencies, a complete database designed by experts according to job analysis and job opportunities in the field of geospatial technology describing job title, job function, tool used, skills and technology ${ }^{1}$. Tier 7 on top left corner is about management competencies (still under process).

Every geospatial field has its own critical work functions defined by the experts, educators, and specialists of geospatial technology (careeronestop, 2015a) which they use to get the desired results. Open source software regarding these aspects is investigated in a later section. If tools to perform these critical work functions are not available as Open Source software existing closed source software can be integrated to encompass all these functionalities. As tier four and five are the main sections of geospatial industry, so a special attention is given to these in this research.

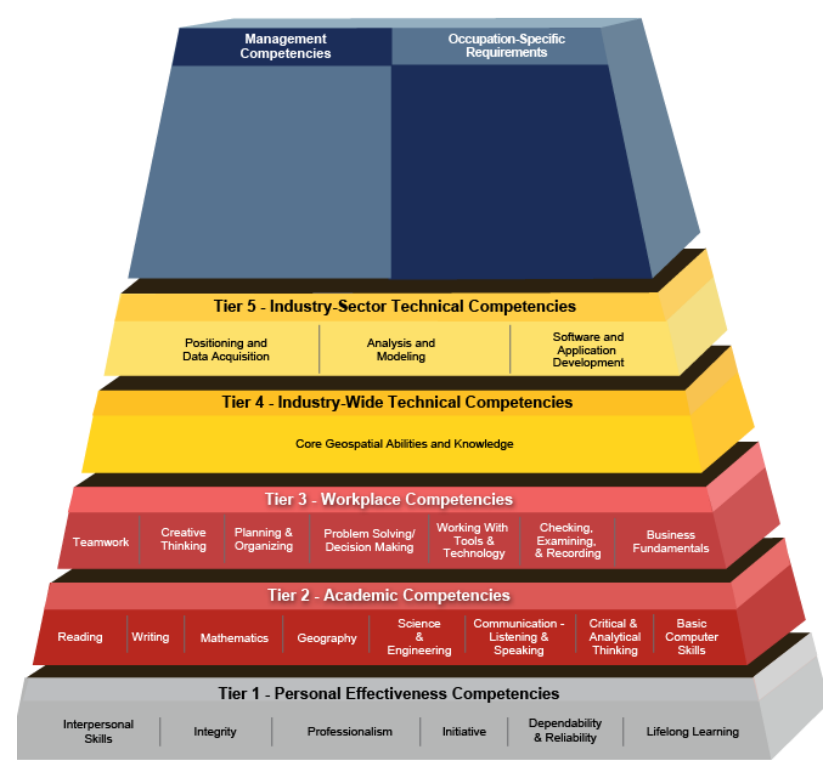

Figure 1: US-Geospatial Technology Competency Model (Source: Careeronestop, 2015)

The main focus of this research lies on tier 4 and 5. Tier four encompasses core geospatial abilities and knowledge having critical work functions of different fields. It describes different industry fields like, earth geometry, remote sensing, GIS, and cartography etc.

\section{In the GTCM, Geospatial industry is divided into three sectors}

a) Positioning and Data Acquisition

This part is about handling of geospatial data. It tells how data is acquired from different technologies like Global Positioning System (GPS), Total Station etc. This also includes factors which affect the data quality. It describes data collection, capturing, and how technologies get georeferenced observations and measurements (Careeronestop, 2015). And later on the focus is on how geospatial data is treated in Open Source software.

b) Modelling and Analysis
This part describes the analysis and application knowledge of analytical functions of geospatial software tools. They have their own critical work functions.

c) Software and Application Development

This part deals with design, development, and customization; it does automation to routine task and defines end user interfaces. It describes the competencies of geospatial software programs, and geospatial databases.

Investigation of GTCM opens a new horizon toward geospatial technology. With the help of GTCM, academia can design supporting courses and curricula to connect geospatial industry and academia to empower open geospatial education. This is one of our motives to use GTCM for developing an Open Source geospatial certification model.

\section{FREE AND OPEN SOURCE SOFTWARE}

The properties of free and Open Source software (FOSS) were fundamentally defined by the Free Software Foundation (http://www.gnu.org/philosophy/free-sw.en.html) with the freedoms to run the program for any purpose, to study how the program works, and change it, to access the source code, and to redistribute copies of your modified versions. Other types of software are categorized as non-free or proprietary.

FOSS is claimed to be reliable, popular and having good performance (Wheeler 2015) and is distributed under the licenses that comply with Open Source definition (https://opensource.org/licenses). The design, development and usage of FOSS in the geospatial domain is flanked by the open standards of the Open Geospatial Consortium (OGC) regarding geospatial interoperability. Open source geospatial software is developed since many years by a world-wide developer community. An important role plays the OSGeo Foundation promoting the ideas about open geospatial software, data, and education by providing financial, organizational and legal support to the broader Open Source geospatial community. Famous OSGeo projects for web mapping are degree, Geoserver, Mapbender Open Layers. OSGeo includes Desktop application as well GRASS GIS, QGIS and focuses on geospatial libraries like GDAL/OGR (http://www.osgeo.org/). The OSGeo foundation has its own OS Geo community, member area, events, and education promotion program. Moreover, OSGeo local chapters are supported by foundation to promote local users and developers as well as OSGeo's mission and goals.

Based on the Memorandum of Understanding between International Cartographic Association, OSGeo Foundation, and ISPRS (http://icaci.org/tag/isprs/) led to the implementation of the ICA-OSGeo-Lab imitative with its mission "Making geospatial education and opportunities accessible to all" (http://www.geoforall.org/). The initiative is quite successful with 106 labs worldwide (as of April 2016).

Discussions in this initiative and the growth and maturity of geospatial Open Source software initiated the idea to develop a framework for a worldwide applicable Open Source certification approach.

Also traditional software vendors are supporting the Open Source approach. ESRI for example supports the Open Source software and encourages participation in the Open Source community with Open Source products. It is recommended to

1 http://www.onetonline.org/find/quick?s=geospatial 
join open and closed software in a hybrid relationship (Esri, 2011 and http://www.esri.com/software/open).

\section{MOTIVATION AND JUSTIFICATION FOR RESEARCH}

The analysis of different certifications and their contribution towards the geospatial industry workforce needs is the main motive behind the new Open Source certification approach. The new certification will not only endorse the expertise in candidates but also it is easy for employee to choose an employer for specific work force. The certification could be granted from the OSGeo foundation and universities who joined the ICA-OSGeo Lab Initiative. This certification will realize the industrial and academic needs of geospatial work force.

\subsection{Industry and academic experts opinion}

During the research industry visits and interviews were conducted to get feedback about the proposed certification model and its business aspects. Interviewees were selected from a diverse group of business contacts with diverse backgrounds, representing academia and companies of varying sizes (from one-man start-ups to large companies).

Bill Hodge, GISP-Executive Director GIS Certification Institute, explained the criteria to have an Open Source certification. According to him "the two foundations of geospatial best practices are the GIST Body of Knowledge, and GTCM." Any certification directed toward Open Source programming and software has to be built on those. He agrees, that "Open Source certification will be a good addition to the geospatial field at some point in the future!"

Rodney D. Jackson, Davidson County Community College agreed and liked the idea and provided some feedback.

Dietrich Schröder, Stuttgart University of Applied Sciences, Germany, was rather critical of the idea expressing some disappointment with Open Source due to its maintenance and stability. Proprietary software has its professional applications and is stable. He concedes that Open Source certification may be useful and help in academic sector specifically. But the quality of certification should be maintained. In the education of undergraduates Open Source GIS will be used instead of the former system.

Wassilios Kazakos, DISY software company, Germany, seconded the idea; the certification would help him evaluating job applicants.

Hui Li, Fichtner Consulting Stuttgart, is interested in application and development of Open Source software. He appreciates the certification approach.

Ernest McCutcheon, managing director Digital data services, Germany, spoke about the government and private issues regarding Open Source software usage. He mentioned that authorities are bit reluctant to use OS software because of its instability and rapid changes. Nevertheless, he added that Open Source certification is a good option for new or entry level users.

Dieter Uckelmann, Stuttgart University of Applied Sciences, Germany, promoted the idea for business model and SWOT analysis. This analysis will be provided in next section.

In the interview during FOSS4G Europe conference Jeff McKenna, President OSGeo Foundation until 12/2015, liked the idea for the Open Source certification model. He advocated the accreditation from OSGeo and encouraged the business idea to professionalize the certification with different projects and to spread the certification model within the OSGeo community.
Jachym Cepicky, Open Source GIS Software consultant and developer, secretary of Board of Directors at OSGeo Foundation, Czech Republic, supported the idea to launch Open Source certification as well as warned about some political and social aspects for a new business launcher.

Martin Scherrer, State Institute for Environment, Measurements, and Nature Conservation Baden-Württemberg, Germany, was in favor of certification. But he suggested that it should include Open Source and closed source solutions.

After the discussions and interviews, the way to a new certification appeared meaningful but also courageous. All discussions and results lead towards the idea of empowering Open Source geospatial education and business.

\subsection{Survey analysis and results}

An online survey on Open Source geospatial certification was conducted through the Internet. Industry and academia was invited to participate ${ }^{2}$. The objective was to know

1. The target group and audience for certification, where we can offer this certification, and who can benefit in academia or industry;

2. How many people are using Open Source geospatial software, and which type of OS software they use;

3. How people think about Open Source certification regarding the fostering of open geospatial education and the competency of geo professionals;

4. Whether their organizations require or offer certification.

The numbers of responses was 105, from USA, Canada, Europe, Asia and United Arab Emirates. The analysis was based upon the qualification of the participant and how much they have experience in geospatial industry (more or less than 5 years). And it describes the comments about launching a new certification in market whether it is useful or not.

Qualification of the participants starts from diploma to $\mathrm{PhD}$. Masters in science (MSc) were most hold by the participants. In all categories professionals having more than 5 years of experience contributed significantly with their opinion. The participants belonged to a wide range of fields of work, i.e. Demographics, Water Resources Engineering, Marine, Earth and Atmospheric Sciences, Anthropology, Environmental sciences.

Generally Open Source certification is appreciated as useful for geospatial education and research. The participants belonging to companies, universities, as well as self-employed are using many Open Source software in their daily business. The analysis shows the highest value for QGIS. Moreover, Grass, PostGIS, Map Server, and a long list of newer Open Source software packages were mentioned (see Fig. 2).

\footnotetext{
2 https://docs.google.com/forms/d/ 1FPvv_QgR8zMCdFzqGgrm5zLT8KvC7j4VTmXTtflYnGk /viewanalytics
} 


\section{Percentage OS Software Users}

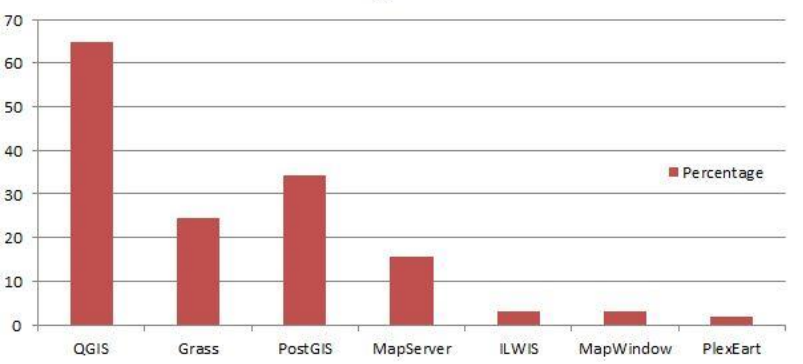

Fig. 2: Open source software demand and use

Further findings show that Open Source certification is rarely given. Most of the respondents believe that certification will increase the competency of geospatial professionals. A high percentage replied in favour of OS certification. However, some participants were totally against Open Source certification because of missing worldwide available standards.

The result and the discussion with experts confirmed the idea to launch geospatial certification. Launching a new Source certification model will enhance the capabilities, skills, and knowledge of geospatial professionals.

\section{DEVELOPED OPEN SOURCE CERTIFICATION MODEL}

\subsection{Structure}

According to the GTCM's three sections of geospatial industry sectors the proposed Open Source certification model is subdivided primarily into three main categories as shown in Figure 3. Moreover, there is one optional sector "Geospatial Project Management" which is developed according to URISA's "Geospatial Management Competency Model" (GMCM, http://www.urisa.org/resources/geospatialmanagement-competency-model.

Each main category contains $2-3$ sub-categories from associate level to expert level.

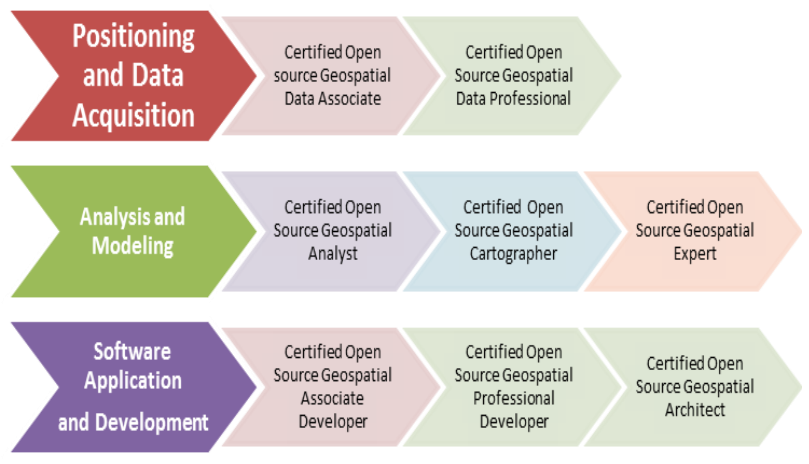

Figure 3: Developed Certification Packages

1) Positioning and data acquisition: The model includes two certification packages for positioning and data acquisition. The Certified Open Source Geospatial Data Associate understands the data acquisition principles and tasks involved in acquisition, creation, and organisation of geospatial data. The Certified
Open Source Geospatial Data Professional level provides advanced expertise including data accuracy and consultancy.

2) Analysis and Modelling: Analysis and modelling is a core competence of the geospatial industry. In this sector applicants have knowledge and application of the analytical functions. The Certified Open Source Geospatial Analyst understands the analytical approach and provides analysis techniques. He can demonstrate and perform different geospatial analysis.

In this sector we plan two more subdivisions of certification.

i. Certified Open Source GIS Analyst and

ii. Certified Open Source Remote Sensing Analyst.

The GIS Analyst can perform basic GIS as well as network and raster based analysis methods whilst the Remote Sensing Analyst has his strengths in analysis of remotely sensed data.

Certified Open Source Cartographer and Certified Open Source Geospatial Expert are two more distinctive sub-categories of analysis and modelling. The cartographer investigates map design and data presentation. The geospatial expert understands analysis of data in depth acquired in several years of experience before applying for this certification. He monitors analysis and modelling processes.

3) Software application and Development: The software application development is the most challenging part. Due to high demand from the industry we plan tree levels of expertise: Associate, Professional, and Architect.

Certified Open Source Geospatial Associate Developer is an entry level certification, which focuses on basic knowledge and programming concept whilst in professional certification level application development and customization of Open Source software packages are carried out. Moreover, automation of manual processes is investigated. The Certified Architect composes different packages, services, and data sources in order to realize

\subsection{Software applied}

According to the survey a large community is using Open Source software, but researchers, companies, and professionals often need hybrid combinations of Open and Proprietary Software (see also the approach of Petras et al. 2015). Nevertheless we tried to assign mainly Open Source packages to the different certification packages as depicted in Table 3.

\begin{tabular}{|l|l|}
\hline Certification Name & Open source Software \\
\hline $\begin{array}{l}\text { Certified Geospatial Analyst- } \\
\text { Remote Sensing and GIS, } \\
\text { Certified Cartographer }\end{array}$ & QGIS and GRASS \\
\hline $\begin{array}{l}\text { Certified Open Source } \\
\text { geospatial associate developer, } \\
\text { Professional Developer }\end{array}$ & $\begin{array}{l}\text { Python, PostgreSQL, } \\
\text { MySQL, ECMASCript, } \\
\text { JQuery, Open Layers, JSP, } \\
\text { ASP }\end{array}$ \\
\hline $\begin{array}{l}\text { Certified Open source } \\
\text { geospatial architect }\end{array}$ & $\begin{array}{l}\text { PostgreSQL, MySQL, } \\
\text { JQuery, Geoserver, } \\
\text { Leaflet, Open Layers, } \\
\text { nodeJS, JSP, ASP, } \\
\text { ArgoUML }\end{array}$ \\
\hline
\end{tabular}

Table 3: Open Source Software Investigation 


\subsection{Examination}

The examination will consist of two parts, firstly an examination which can be performed through the Internet or at one of the partnering universities, secondly a a home based exercise will be given to the candidates.

The exam will be based upon the certification body of knowledge (CBOK). The candidate has to score at least at a certain threshold (like 60\%) in order to pass the exam. The exam itself can be based on multiple choice question and answers with limited time duration.

The purpose of the second part is to check the competencies of the candidate and his scientific skills. Knowledge principles of Open Source software, competencies as well as practical experience and scientific writing capabilities are examined.

\subsection{Recertification}

Recertification should be undertaken $3-5$ years after certification. The candidate has to apply for recertification and to prove continuous professional practice, education, training, and engagement in professional organisations.

\subsection{Accreditation}

To evaluate the competency and credibility, Open source Geospatial certification tries to get accreditation according to ISO/ICE 17024:2012 (Conformity assessment-General requirements for bodies operating certification of persons) by OSGEO Foundation or any other accreditation body.

\section{BUSINESS CASE AND SWOT MODEL}

To establish an business related to the proposed certification model is a highly challenging task. We conclude that certification should ould be launched to promote geospatial education. However The certification can be launched after certification survey analysis, personal interviews, email discussions (ICA-OSGEO labs) and expert's opinion that support the idea of Open Source certification and can bring a new geospatial business in the market. In my suggestion, business idea cannot be generated on the basis of just Open Source certification only but consultancy in geospatial business is also important. In the start company will provide the advices and solutions from data acquisition to application development and will try to collaborate with university education and industry.

The Strength, Weakness, Opportunities, and Threats model define positive and negative aspects of a product and can serve as a tool to support further business decisions.

\begin{tabular}{|c|c|}
\hline Strengths & Weakness \\
1) Competency based skill & 1) Reliability and \\
certification. & maintenance issue. \\
2) promotion of business and & 2) Weak geospatial business \\
job opportunities & in Open Source \\
3) Innovation & 3) support system for Open \\
4) Broaden the industry's & Source issue \\
capabilities & 4) Available certifications on \\
5) Empowerment for & Open Source are very rare. \\
geospatial education & 5) Decision making with \\
6) Proper and flexible & Open Source certification is \\
alternative to proprietary & difficult \\
\hline
\end{tabular}

\begin{tabular}{|c|c|}
\hline software & \\
7) straight-forward channel to \\
gain expertise and \\
competence over open-source \\
software & \\
8) provide legitimacy and & \\
understanding of Open & \\
Source tools and functionality & \\
9) Proper and flexible \\
alternative to proprietary \\
software certification \\
10) Market analysis and trend \\
support Open Source \\
certification
\end{tabular}

Table 4: SWOT analysis of the certification business approach.

\section{FUTURE WORK}

Future work will explore the feasibility of this approach. The concept seeks the accreditation by the OSGeo Foundation (and other bodies) and international support by a powerful group of geospatial scientific institutions to achieve wide and international acceptance for this Open Source geospatial certification model.

\section{REFERENCES}

Association of American Geographer (AAG), 2012. The Geospatial Job Market. http://www.aag.org/galleries/jobscareers-files/Geospatial_panel_notes_2012.pdf [2016-04-05]

American Society of Photogrammetry and Remote Sensing (ASPRS), 2016a. Introduction to ASPRS CertificationProgram. Available from: http://www.asprs.org/CertificationProgram/Introduction-to-ASPRS-Certification-Program.html [2016-04-05]

American Society of Photogrammetry and Remote Sensing (ASPRS), 2016b. Certification Examination Matrices http://www.asprs.org/Certification-Program/CertificationExamination-Matrices.html [2016-04-05]

American Society of Photogrammetry and Remote Sensing (APSRS), 2016c. Certification and Recertification Guidelines http://www.asprs.org/Certification-Program/Certification-andRecertification-Guidelines.html [2016-04-05] 
Careeronestop, 2015a. Geospatial Technology Competency Model. http://www.careeronestop.org/competencymodel/faq.aspx [2016-04-17]

Careeronestop, 2015b. "Building Blocks" for Competency Models. http://www.careeronestop.org/CompetencyModel/pyramid_definition.aspx [2016-04-17]

Christl, A., 2014. Open Source Geo Certification. FOSS4G 2014, Portland, https://vimeo.com/106231984 [2016-04-05].

Davis, P. 2015. Educating 21st Century Geospatial Technology Industry Workers with Open Source Software. OSGeo Journal, vol. 14, no. 1, https://journal.osgeo.org/index.php/journal/issue/viewIssue/35/6 [2016-04-05].

DiBiase, D., DeMers, M., Johnson, A., Kemp, K., Luck, A. T., Plewe, B., and E. Wentz, (eds 1) 2006, Geographic Information Science and Technology Body of Knowledge. http://www.aag.org/galleries/publications-

files/GIST_Body_of_knowledge.pdf [2016-04-05].

DiBias, D., 2010, The New Geospatial Technology Competency Model: Bringing Workforce Needs into Focus, Journal of Urban and Regional Association, vol. 22, no. 2, pp 55-72 http://www.urisa.org/clientuploads/ $\neg$ directory/ $\neg$ Documents $/ \neg$ Jo urnal/Vol22No2.pdf [2016-04-06].

Esri, 2011: Open Source Technology and ESRI http://www.esri.com/news/arcnews/spring 11 articles/opensource-technology-and-esri.html [2016-04-17]

Esri, 2015. Benefits of Esri Technical Certification. http://www.esri.com/ᄀᄀtraining/main/certification/certificationbenefits [2016-04-10].

Ennis M. R., 2008. Competency Models: A Review of the Literature and The Role of the Employment and Training Administration (ETA) http://www.careeronestop.org/COMPETENCYMODEL/info_documents/-

OPDRLiteratureReview.pdf [2016-04-17].

gvSIG Association, 2015. gvSIG Certification. http://www.gvsig.com/en/services/certification [2016-04-05].

Metaspatial Institute, 2015: The metaspatial Institute: Certifying Open Geospatial. http://www.metaspatial.net/en/institute [2016-04-05].

Horak, J. 2015. The role of certification in GIS\&T education. Procedia - Social and Behavioral Sciences 174 (2015) $1356-$ 1363 https://www.researchgate.net/publication/277651509_The_Role_of_Certification_in_GIST_Education [2016-05-03]

Johnson, A. B., Sullivan, D., 2010: Geospatial education at U.S. community colleges: Background, challenges, and opportunities. Journal of Urban and Regional Association, vol. 22, no. 2, pp 5ff http://www.urisa.org/clientuploads/directory/ $\neg$ Documents/-Journal/Vol22No2.pdf [2016-04-06].

Oracle, 2015. Oracle Certification http://education.oracle.com/pls/web_prod-plq-dad/db_pages.getpage? $\neg$ page_id=39\&-

p_org_id=897698183\&lang=US [2016-04-10].

Petras, V., Petrasova, A., Harmon, B., Meentemeyer, R. K., Mitasova, H. 2015. Integrating Free and Open Source Solutions into Geospatial Science Education. ISPRS Int. J. Geo-Inf. 2015,
4(2), pp. 942-956; http://www.mdpi.com/22209964/4/2/942/pdf [2016-05-01].

PIMS - Pakistan Institute of Modern Studies, 2015. Professional Certification Programme. http://va.edu.pk/ᄀhome.php [2016-04-17]

Richardson, D., 2013: Getting a Job in Geography and GIS. ArcNews, http://www.esri.com/esri-news/arcnews/spring13articles/getting-a-job-in-geography-and-gis [2016-0405]

Somers, R., 2004. Demystifying Certification. Available from:https://ceoas.oregonstate.edu/giscience/files/Somers_Certi fication_vs_Certificates.pdf [2016-04-06]

Steudler, D., Törhönen, M.-P., Pieper, G. 2010. FLOSS in cadaster and land registration-opportunities http://www.fig.net/pub/fao/floss_cadastre.pdf [2016-04-15].

Wheeler, D. A., 2015. Why Open Source Software / Free Software (OSS/FS, FLOSS, or FOSS)? Look at the Numbers! http://www.dwheeler.com/oss_fs_why.html [2016-04-17].

Wikle. T. A., 2014. A look for GIS certification program and their challenges for higher education. Journal of Urban and Regional Association, vol. 27, no. 1 http://www.urisa.org/clientuploads/directory/Documents/Journal/Vol27No1.pdf [2016-04-05]. 